\title{
The transformation of motherhood in Quebec
}

Previously published at www.cmaj.ca

Babies for the Nation: The Medicalization of Motherhood in Quebec 1910-1970

Denyse Baillargeon; Translated by W.

Donald Wilson

Wilfrid Laurier University Press; 2009.

$\mathrm{T}$ he heart-rending death of a baby was an all too familiar trial endured by many families in the early part of the 20th century. At that time, Quebec's infant mortality rates were the highest in Canada; a situation that was regarded both as a humanitarian emergency and as a black eye for Quebec nationalism. This is the intriguing topic addressed by Université de Montréal historian Denyse Baillargeon in this book, which has now been translated into English.

The complex cultural and economic reasons for Quebec's high infant mortality are well-described in Babies for the Nation, but Baillargeon's real interest lies in the reactions to the problem, which are no fewer and no

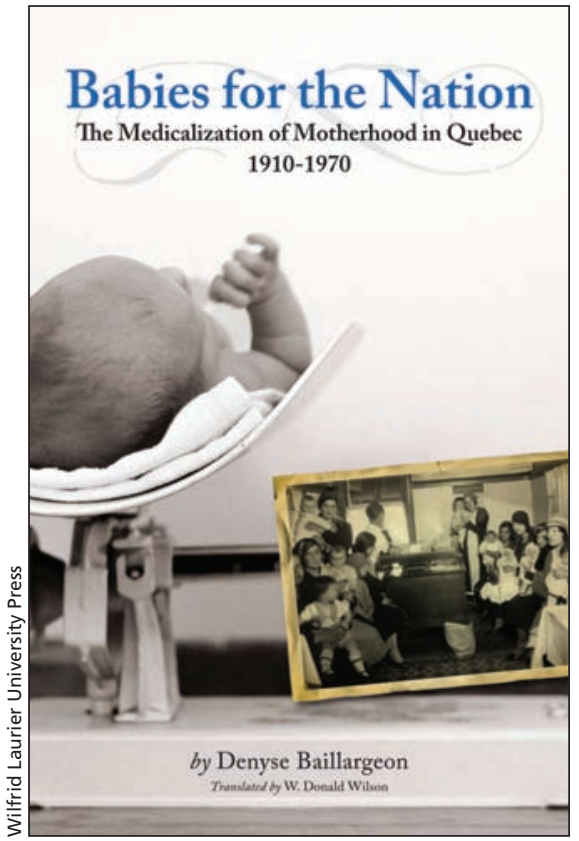

government. As suggested by the subtitle, these interactions transformed pregnancy and motherhood from family concerns into medical conditions that demanded close supervision by trained professionals. This is an acade-

\section{These interactions transformed pregnancy and motherhood from family concerns into medical conditions.}

simpler than its causes. Her study focuses on the mothers of Quebec and their interactions with the groups who took an interest in lowering the province's infant mortality rate: private physicians, public health physicians, nurses, volunteer organizations, the insurance company Metropolitan Life, religious groups and the Quebec mically ambitious book, broad in scope and thoroughly researched. Judged by the standards of scholarly press, however, it manages to be quite readable.

Baillargeon's approach is unabashedly feminist, but not dogmatically so. She frequently admonishes the medical patriarchy of the time, but observes that “...women gradually sought out this medical supervision ... to the extent that ... they perceived concrete advantages in it for their baby, their family, and themselves."

Babies for the Nation is academically rigorous and well-written, but is it relevant to a contemporary readership in Canada where infant mortality is much decreased, and the notion of a dictatorial and male-dominated medical system is increasingly archaic?

The answer is yes: Baillargeon's book depicts the conflicts among the groups involved in public health and politics that is likely no different today. These include financial self-interest, territoriality among professional groups, nationalist concern over the sheer size of the francophone population in Quebec and the doctrinaire involvement of religious groups. Evidently, the concept of "fewer dead babies" could not persuade those concerned to put aside these political agendas for the common good. Arguably any recent issue in public health suffers from interference that is equally political.

As a coda to this sobering realization, Baillargeon offers an ironic caution about unintended consequences: This same process of medicalized motherhood also brought access to contraception and a striking decline of the birth rate in Quebec. One wonders, what the nationalist pediatrician, who declared that a decreased infant mortality rate would provide Quebec with a "victory of the cradles!" over Anglophone Canada, would think.

\section{Paul Moorehead MD}

Pediatric Hematology / Oncology

Fellow

Children's Hospital of Eastern Ontario Ottawa, Ont. 